\title{
Knowledge, Attitudes and Beliefs on HIV/AIDS among Tertiary Students in Papua New Guinea
}

\author{
Orathinkal Jose $^{{ }^{*}}$, Keri Totona ${ }^{2}$, Alphonse Begani ${ }^{2}$ Tuka Andew ${ }^{2}$, Bob Tombe ${ }^{2}$, Rose Begani ${ }^{2}$ \\ ${ }^{1}$ Divine Word University, Madang, Papua New Guinea; ${ }^{2}$ Department staff of the Environmental Health, Divine Word University, \\ Madang, Papua New Guinea. \\ Email: jorathinkal@dwu.ac.pg, orathinkal@yahoo.co.uk
}

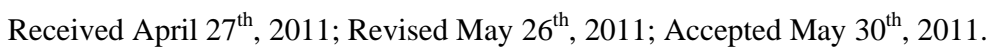

\begin{abstract}
This cross-sectional study among 1597 tertiary level students, 757 (48\%) males and 832 (52\%) females (9 respondents no mention of gender), from 12 institutions, across Papua New Guinea, examined their level of knowledge, attitudes and beliefs about HIVIAIDS. The study revealed that the majority of the students have a very good knowledge of HIVIAIDS; in general students have a considerate and compassionate attitude towards those infected with HIVIAIDS; and the students have positive and healthy attitudes and beliefs regarding HIVIAIDS. Among the demographic variables of gender, province and the institution of their study a significant difference showed in their levels of knowledge and also a statistically significant association was found between beliefs and knowledge. Interestingly, about 58\% of the students think that HIVIAIDS is a punishment from God. Almost half (46.5\%) of the respondents think that learning about sex and the use of condoms could also encourage young people to engage in more frequent sex. Although, in general the students have a very good knowledge, they indicate the need for more sex education and awareness programs about HIVIAIDS that could be given in high schools.
\end{abstract}

Keywords: HIVIAIDS, Sex Education, Tertiary Students

\section{Introduction}

Acquired Immune Deficiency Syndrome or Acquired Immunodeficiency Syndrome (AIDS) is a disease of the human immune system caused by the human immunodeficiency virus (HIV). The HIV was first recorded in 1981 in gay men in USA. Since then it has spread to a number other countries. Statistics, as provided by UNAIDS and WHO in 2007, show that over 33 million people throughout the world are now with HIV/AIDS causing it to be one of the most devastating diseases mankind has ever faced [1].

The threat posed by HIV/AIDS to the socio-economic, demographic and medical dimensions continues to increase. Since the first case of HIV/AIDS was identified in 1981, the number of officially reported cases increased to 43,587 by the end of 2000 . Within this period, the virus has been identified among people in the entire world and among all socio-demographic groups [8].

The first case of HIV infection in Papua New Guinea (PNG) was detected in 1987. In 2006, there were about 18,500 confirmed cases by blood test and the best latest estimate, in 2007, of people living with HIV/AIDS in
PNG is about 56,175. Estimated AIDS related deaths in PNG so far is 6000 and estimated AIDS orphans areabout 3730. The number of people under Anti-Retroviral Therapy (ART) is about 3000 [7].

According to the 2009 STI, HIV and AIDS Annual Surveillance Report, issued by the National Department of Health as reported in Papua New Guinea: National HIV and AIDS Strategy, 2011-15, (pp. 15-19), in December 2009 [8], the total number of people living with HIV in PNG was estimated to be 34,100 (31,000 adults aged 15 or more and 3100 children and adolescents). This was equivalent to a national prevalence of $0.9 \%$ in the 15 to 45 age group. It was estimated that approximately 3200 people were infected with HIV in 2009, while around 1300 people were estimated to have died from AIDS in the same year. To the end of 2009, a cumulative total of 11,520 people were estimated to have died because of HIV-related illness and 5610 children had become orphans, (losing one or both of their parents), as a result of the epidemic.

Based on the 2010 estimates and projections, the period of the most rapid increase in new HIV infections was between 1999 and 2005. Since 2006, there has been 
a continued upward trend in national prevalence, but at a less rapid rate. It is estimated that the national HIV prevalence among adults will be $1.0 \%$ in 2015 . The HIV epidemic has not followed the same pattern in all four regions of PNG. Estimates of adult prevalence were developed for the four PNG regions: Highlands: adult prevalence was estimated to be $1.02 \%$ in 2009 , with indications that a plateau may have been reached. Southern: adult prevalence was estimated to be slightly higher at $1.17 \%$, while the epidemic may also have started to level off. This data is largely derived from the National Capital District and is not indicative of prevalence in other parts of the region. Momase and New Guinea Islands: prevalence is estimated to be substantially lower than in the Highlands and Southern regions, at $0.63 \%$ in Momase and $0.61 \%$ in New Guinea Islands [10].

In 2009, 90\% of all new case reports of HIV infection were from five provinces, Port Moresby and one large town. This included all Highlands provinces Western Highlands (26.3\%), Eastern Highlands (11.2\%), Enga (11.0\%), Southern Highlands (6.1\%), Simbu (5.7\%), National Capital District (NCD) (20.7\%) and Morobe (9.0\%). The breakdown of HIV case reports by region in 2009 was: Highlands Region 60\%; Southern Region 26\%, including 21\% from National Capital District; Momase Region 11\%, and New Guinea Islands Region 2\%.

From 1987 to 2009, females accounted for 56\% of all reported cases of HIV infection (excluding cases where sex was not reported), and males for $43 \%$. The higher number of reports of HIV in females may reflect the nature of the surveillance system, which is heavily reliant on case reports from antenatal centres (ANC), or a genuinely higher prevalence among women. The latter appears to be the more likely explanation as the HIV case detection rate among clients of voluntary counselling and testing (VCT) centres in 2009 was $4.7 \%$ in women compared to $3.7 \%$ in men.

Under the National Strategic Plan a number of key achievements have been made within this short of span of time. Some of the key achievements are: approval of PNG's first National HIV Prevention Strategy; significant progress in mainstreaming HIV prevention in the key government sectors of education, law and justice, and transport; $100 \%$ of schools provided life skills based HIV and AIDS education in 2009; Rapid roll-out of ART: $75 \%$ of people in need of ART on treatment in 2009, compared to $23 \%$ in 2006; significant expansion of HIV service delivery through civil society, particularly for care, support and treatment services provided by faith based organizations; increase in the number of condoms distributed by non-government organisations (NGOs) from 3.3 million in 2007 to 8 million in 2009; increase in the number of HIV testing sites from 35 in 2006 to 251 in 2009. The number of HIV tests increased from around 15,000 in 2006 to more than 123,000 in 2009; a rapid increase in the knowledge pattern of HIV/AIDS [11].

Although knowledge of the pattern of the HIV epidemic in PNG has improved, there is still a lack of quality epidemiological and behavioural data to guide the planning of the national response, particularly prevention programming. Improving the availability and quality of epidemiological and behavioural data so the response can be tailored to the reality of the epidemic is a high priority for the NHS.

This research aimed to examine how well the tertiary students across the country are being informed or ignorant of this dreaded disease, because knowledge is the best tool for prevention of diseases as it has the power to influence change in attitudes and practices. If all tertiary students are better informed on HIV/AIDS, this will enhance the principle of prevention thus greatly helping the nation in combating the epidemic. The fact that tertiary students are at risk of AIDS has important implications for the wellbeing of the nation as a whole, simply because PNG, being a young nation with very few tertiary graduates, is urgently in need of qualified personnel for its development.

The majority of previous studies on HIV/AIDS (in the USA) at tertiary institutions focused on knowledge, awareness and practices of students. All of the studies indicated that students were generally knowledgeable about the causes and modes of transmission of HIV/ AIDS. They were able to specify the activities that constitute high-risk behaviour as well as the best ways to protect themselves from HIV infection [3]. They also tended to recognize HIV/AIDS to be a problem on campus [6].

A study done in Nigeria, has shown that youths are the most vulnerable to sexually transmitted diseases, including HIV/AIDS, since they are the most sexually active and have been shown to have multiple sex partners and engage in unprotected sex without condoms [4]. The estimated prevalence of HIV among youths, ages 15 - 24 in Nigeria was between $4.4 \%-5.9 \%$ for females and from $1.7 \%-3.3 \%$ for males [12] indicating that females were more easily infected than males.

Some studies from the US have shown that tertiary students are not concerned about AIDS and do not perceive themselves to be at risk [2]. But do the tertiary students in PNG have the same attitude and beliefs towards HIV/AIDS? It is critical for the AIDS campaigners to have the relevant information regarding tertiary students' attitudes toward people with AIDS, students' beliefs about AIDS in relationship to themselves, and those risky behaviors students engage in.

Alcohol use and peer pressure were two important 
factors impacting on the tendency towards casual sex combined with the absence of safe sex practices. Studies also showed that students generally did not consider themselves to be at a serious risk of contracting HIV/ AIDS. This belief is largely a result of students indulging in "othering" the disease, that is the belief that people like drug users, male homosexuals, uneducated people, rural people, black people (in the view of white people) or residential students (in the view of students living at home) are more likely to be infected. Related to this belief is the tendency to stigmatize and avoid those who are known to be HIV-positive [3].

In the absence of an effective treatment or cure for AIDS, a preventive strategy is seemingly the best option that we are left with in preventing the spread of this pandemic. Educational awareness has been one of the most commonly used approaches across the globe. However, there is evidence to suggest that among adolescents and tertiary students an accurate knowledge about AIDS transmission does not necessarily lead to the implementation of safer sexual practices [6]. Health education may be a vital tool that can be used to tackle ignorance, fight prejudice and empower communities to change behavior and even, may be the best way to contain the disease [5].

This research aimed to document tertiary students' attitudes, beliefs and knowledge of HIV/AIDS. This research could support the implementation of PNG's multi-sectoral National Strategic Plan for HIV and AIDS (NSP). There are existing awareness campaigns by all stakeholders concerned such as the National Government through the establishment of the National AIDS Council Secretariat, Non-Government Organizations (NGOs) such as World Health Organization (WHO) and faith based organizations such as Anglicare, who have one aim and that is to fight this dreadful disease. The findings of this study could better inform them regarding the knowledge and attitudes of educated youth of the country and if needed to reorganize their policies and programmes. It could also serve as a baseline for educators including teachers at all levels of education, peer educators and health professionals at all sectors within the country. This study had the following objectives:

a) to document tertiary students' attitudes towards people with AIDS;

b) to assess students' level of knowledge about HIV/ AIDS;

c) to document students' beliefs about HIV/AIDS;

d) to investigate if there is a relationship between some demographic variables such as age, gender, study institution and knowledge about AIDS.

In order to achieve the above objectives this study attempted to answer following research questions:

1) What is the level of knowledge of tertiary students

\section{on HIV/AIDS?}

2) What is the attitude of tertiary students towards HIV victims?

3) What are beliefs of tertiary students regarding HIV/AIDS?

4) Is there an association between the gender, and study institution of the students and their knowledge about HIV/AIDS?

\section{Methodology}

\subsection{Study Design and Participants}

A cross sectional survey conducted was conducted among tertiary students in Papua New Guinea. The participants of this study were 1597 tertiary students: 757 males and 831 females (9 respondents had no mention of gender), from 12 different tertiary institutions across the country (see Table 1 for details).

\subsection{Instruments}

The main mode of gathering information was through a researcher-made questionnaire (refer to 1 ). Besides some demographic questions such as age, gender, religious affiliation, province of origin, institution of study etc., the questionnaire contained a total of 40 statements, 28 of them relating to knowledge and 6 each to beliefs and attitudes of students. Knowledge was categorized into three levels such as very good (A) a score ranging from 85 to 100 , good (B) a score between 75 to 84.99, poor (C) score from 60 to 74.99 , and very poor (D) a score of 0 to 59.99. Although originally it was coded with $1,2,3$ respectively for "Yes", "No", "I do not know", for classification of different levels, the raw score was transformed into a score out of 100 . Higher scores indicate better knowledge.

A content analysis of the completed questionnaire was undertaken and a pilot test was conducted among 20 randomly selected first year students in DWU. This was done to ascertain the face validity and comprehensibility in drafting the final questionnaire. The corrected spilthalf reliability of scale is 86 , with an alpha coefficient of 91. This also served as a validity check which identified obvious errors that were omitted and ambiguous questions were reformulated. The questionnaires were group administered with prior appointments with respective institutions.

\subsection{Sampling Method and Procedure}

A stratified sampling method was used to collect the data for this study. The stratum was the first year students of every tertiary institution across the country. The proportion of the simple size was about $25 \%$ to $30 \%$ of the first year students from each tertiary institution.

Formal letters were written to each of the selected in- 
stitutions to seek approval and assistance from staff and/or lecturers for this study. Upon the receipt of proper response, the researchers travelled to respective institutions to collect the data.

\subsection{Data Management and Analysis}

As soon as all the questionnaires were collected, the responses were coded and analyzed at a DWU computer laboratory using SSPS-15. The main parameter for analysis that was measured between the two categories of students was the different levels of knowledge they had on HIV/AIDS and their attitude towards HIV/AIDS victims. Data was analyzed using descriptive and correlational statistics (t-test, Cross Tabulations, ANOVA, Post
Hoc-Duncan).

\section{Results}

\subsection{Profile of the Sample}

Table 1 shows the demographic profile of the participants.

\subsection{Level of Knowledge}

Table 2 shows the level of knowledge of the participants in four different levels. The level of knowledge was categorized into four levels such as very good (A) a score ranging from 85 to 100 , good (B) a score between 75 to 84.99, poor (C) score from 60 to 74.99, and very poor (D) a score of 0 to 59.99 .

Table 1. Demographic Profile of the participants.

\begin{tabular}{|c|c|c|c|c|c|c|}
\hline & Male & Female & Total & & & \\
\hline Gender & $\begin{array}{c}757 \\
(48 \%)\end{array}$ & $\begin{array}{c}831 \\
(52 \%)\end{array}$ & $\begin{array}{c}1588 \\
(100 \%)\end{array}$ & & & \\
\hline Age range & \multicolumn{3}{|c|}{16 to 48 years (mean age 21 ) } & & & \\
\hline \multirow[t]{13}{*}{ Religion } & & & percent & Province & & percent \\
\hline & Catholic & 607 & 38 & Central & 78 & 5 \\
\hline & Lutheran & 191 & 12 & Gulf & 35 & 2 \\
\hline & United Church & 121 & 8 & Milne Bay & 45 & 3 \\
\hline & SDA & 181 & 11 & Western & 31 & 2 \\
\hline & AOG & 103 & 6 & Oro & 20 & 1 \\
\hline & Christian Revival & 343 & 22 & Morobe & 111 & 7 \\
\hline & Nazaren & 1 & .1 & Madang & 160 & 10 \\
\hline & Anglican & 8 & 1 & East Sepik & 159 & 10 \\
\hline & CRC & 3 & .2 & West Sepik & 54 & 3 \\
\hline & Baptist & 12 & 1 & Eastern Highland & 59 & 4 \\
\hline & Aposotlic & 2 & .1 & Simbu & 89 & 6 \\
\hline & Total & 1572 & 100 & Western Highland & 150 & 9 \\
\hline \multirow[t]{14}{*}{ Institutions } & & & & Enga & 73 & 5 \\
\hline & DWU & 291 & 18 & Sothern Highland & 60 & 4 \\
\hline & UPNG & 261 & 16 & Manus & 47 & 3 \\
\hline & UNITECH & 181 & 11 & West New Britain & 33 & 2 \\
\hline & UOG & 218 & 14 & East New Britain & 183 & 12 \\
\hline & UoVudal & 94 & 6 & New Ireland & 54 & 3 \\
\hline & SMVunapope & 78 & 5 & ARB & 68 & 4 \\
\hline & Holy Trinity & 149 & 9 & Jiwaka & 33 & 2 \\
\hline & SBKaindi & 96 & 6 & Mixed parentage & 22 & 1 \\
\hline & MTC & 90 & 7 & other countries & 14 & 1 \\
\hline & LSoN & 62 & 4 & NCD & 2 & .1 \\
\hline & MATECHCO & 36 & 2 & Central & 78 & 5 \\
\hline & Maritime & 30 & 2 & & & \\
\hline & Total & 1586 & 100 & & & \\
\hline
\end{tabular}


Table 2. Level of knowledge of the respondents.

\begin{tabular}{ccc}
\hline Knowledge Level & Frequency & Percent \\
\hline A (very good) & 702 & 45.9 \\
B (good) & 468 & 30.6 \\
C (poor) & 295 & 19.3 \\
D (very poor) & 64 & 4.2 \\
Total & 1529 & 100.0 \\
Missing & & 68 \\
Total & & \\
\hline
\end{tabular}

As Figure 1 shows, about $46 \%$ of the students have a very good knowledge of HIV/AIDS, about $31 \%$ good knowledge, around $19 \%$ fall within the category of poor and only around $4 \%$ of students have a very poor knowledge.

The level of knowledge was determined by the respondents' answers to 28 statements regarding HIV and AIDS. Given below are the separate answers to each of

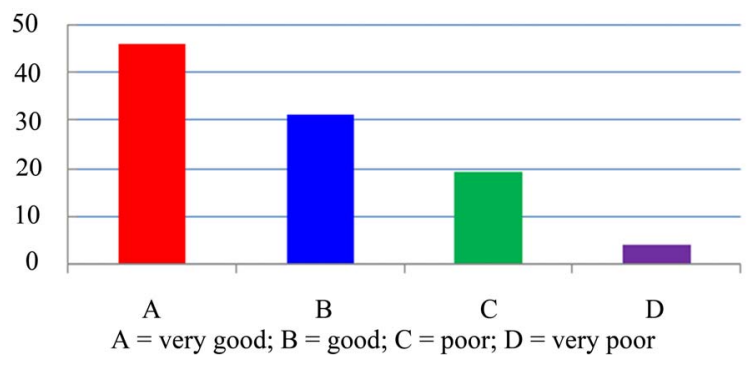

Figure 1. Level of knowledge of respondents.

those statements.

Six statements were meant to examine the attitude of students. Table 3 summarizes the findings on attitude.

\subsection{Attitudes in Regard to HIV /AIDS}

As Table 4 shows, in general the students depict a positive attitude towards those infected with HIV/AIDS.

Table 3. Student's knowledge on HIV/AIDS.

\begin{tabular}{|c|c|c|c|}
\hline \multirow[t]{2}{*}{ Statement on HIV/AIDS with regard to Knowledge } & \multicolumn{2}{|c|}{ Responses } & \multirow[b]{2}{*}{ Do not know Nos. (\%) } \\
\hline & Yes Nos. (\%) & No Nos. (\%) & \\
\hline HIV and AIDS are the same thing. & $285(18)$ & $1228(77)$ & $81(5)$ \\
\hline One can be infected with HIV from an insect bite. & $68(4)$ & $1437(90)$ & $91(6)$ \\
\hline One can tell if someone is infected by HIV just by looking at them. & $210(13)$ & $1303(82)$ & $77(5)$ \\
\hline AIDS is when your immune system has been damaged by HIV. & $1229(81)$ & $77(5)$ & $212(13)$ \\
\hline There is no cure for HIV in Papua New Guinea. & $1174(74)$ & $269(17)$ & $147(9)$ \\
\hline Women are more vulnerable to HIV than men. & $704(44)$ & $469(30)$ & $408(26)$ \\
\hline $\begin{array}{l}\text { If you touch HIV infected blood with your hands you will become infected } \\
\text { (even if there is no cut on your finger). }\end{array}$ & $249(16)$ & $1120(70)$ & $219(14)$ \\
\hline $\begin{array}{l}\text { One could get AIDS by being coughed/sneezed on by the people who are } \\
\text { infected. }\end{array}$ & $32(2)$ & $1429(90)$ & $120(8)$ \\
\hline One could get HIV/AIDS by speaking with those infected. & $13(1.5)$ & $1567(98)$ & $7(0.5)$ \\
\hline $\begin{array}{l}\text { The use of condoms during intercourse greatly reduces the risk of transmitting } \\
\text { AIDS. }\end{array}$ & $681(43)$ & $681(43)$ & $223(14)$ \\
\hline AIDS can be transmitted by holding the hands of those infected, & $13(0.8)$ & $1562(98.3)$ & $14(.9)$ \\
\hline AIDS is caused by bacteria . & $339(21)$ & $996(62)$ & $244(17)$ \\
\hline One can get HIV/AIDS by cleaning sick peoples vomit /pekpek wara/tears. & $89(6)$ & $1238(78)$ & $256(16)$ \\
\hline $\begin{array}{l}\text { AIDS can be transmitted by sharing tattoo blades or needles from an infected } \\
\text { person. }\end{array}$ & $1517(95)$ & $45(3)$ & $26(2)$ \\
\hline AIDS is caused by the same bacteria that cause gonorrhea. & $168(11)$ & $933(58)$ & $487(31)$ \\
\hline By hugging HIV infected people one could get it. & $49(3)$ & $1505(94)$ & $34(3)$ \\
\hline $\begin{array}{l}\text { You can get AIDS from sharing plates, forks, or glasses with an AIDS in- } \\
\text { fected person. }\end{array}$ & $60(4)$ & $1474(92)$ & $54(4)$ \\
\hline People infected with HIV die quickly. & $238(15)$ & $1201(75)$ & $152(10)$ \\
\hline $\begin{array}{l}\text { You can get AIDS from sharing clothes and the same toilet facilities with } \\
\text { those infected with HIV. }\end{array}$ & $65(4)$ & $1381(87)$ & $147(9)$ \\
\hline AIDS can be transmitted through/by blood. & $1530(96)$ & $32(2)$ & $26(2)$ \\
\hline AIDS can be transmitted through/by semen. & $1417(89)$ & $58(4)$ & $111(7)$ \\
\hline AIDS can be transmitted through/by vaginal fluid. & $1449(91)$ & $62(4)$ & $77(5)$ \\
\hline AIDS can be transmitted through/by feces. & $91(6)$ & $1178(74)$ & $318(20)$ \\
\hline AIDS can be transmitted through/by tears. & $50(3)$ & $1372(86)$ & $166(11)$ \\
\hline AIDS can be transmitted through/by sweat. & $51(3)$ & $1338(84)$ & $195(13)$ \\
\hline AIDS can be transmitted through/by urine. & $129(8)$ & $1112(70)$ & $333(21)$ \\
\hline AIDS can be transmitted from mother to child. & $1474(92)$ & $74(5)$ & $39(3)$ \\
\hline AIDS can be transmitted through/by saliva. & $287(18)$ & $888(56)$ & $411(26)$ \\
\hline
\end{tabular}




\subsection{Respondents' Beliefs Regarding HIV/AIDS}

Six statements with "Yes” (agree), "No" (do not agree), and "I don't know" response categories were used to investigate students' beliefs about AIDS in relationship to themselves. Responses to belief statements were not assigned a point value. Therefore, subjects did not receive a score for their beliefs about AIDS; instead, each statement was assessed individually. Table 5 presents the summary of these findings.

\subsection{Association between Knowledge and Some Demographic Variables}

The fourth objective of this study was to examine whether there is a difference in the knowledge score depending on the demographic variables. Tables 6 and 7 show the knowledge score according to the respondents' province, institutions and religious affiliation.

As Table 8 shows, a one way ANOVA was used to test for knowledge on HIV/AIDS difference among 22 provinces. Knowledge on HIV/AIDS significantly differed across 22 provinces, $F(22,1554)=1.95$, $\mathrm{p}=.005$. Post hoc analyses were performed using the Scheffé tests to identify where differences exist. But the analyses could not identify where the exact difference lies; it could be due to the fact that the difference is moderate.

As the same Table 8 shows, a one way ANOVA was used to test for knowledge on HIV/AIDS difference among 12 institutions. Knowledge on HIV/AIDS significantly differed across 12 Institutions, $F(11,1574)=$ 3.73, $\mathrm{p}=.000$. Post hoc analyses were performed using the Scheffé tests to identify where differences exist. The analyses revealed that University of Vudal (UoV) differed significantly from Holy Trinity $(p=.004)$, MTC $(p$ $=.002)$ and MADTECHC $(\mathrm{p}=.001)$ and no other differences were found.

ANOVA test for knowledge on HIV/AIDS difference among different religious affiliations as well as Occupations of the parents did not indicate a statistically significant difference. The $\mathrm{F}$ value for religious affiliations was $F(10,1561)=.591, \mathrm{p}=.823$ and for the Occupation of the parents was $F(5,1524)=1.788, \mathrm{p}=.134$.

Chi-squared $\left(\chi^{2}\right)$ test showed statistically significant $\left[\chi^{2}(1, \mathrm{n}=1588)=23, \mathrm{p}<.000\right]$ but moderate difference between the level of knowledge of male and female students. As the graph in Figure $\mathbf{3}$ shows the males are slightly better informed than their female counterparts.

\subsection{Association between Beliefs and Knowledge}

A one way ANOVA tested (Table 8) whether knowledge on HIV/AIDS differed according to the beliefs of the respondents. An analysis on the statement' "People with $H I V$ should be separated from normal community”, showed that knowledge on HIV/AIDS significantly dif-

Table 4. Students' attitude toward HIV/AIDS.

\begin{tabular}{lcc}
\hline & & \multicolumn{2}{c}{ Responses } \\
\cline { 2 - 3 } Questions/Statements on Attitudes & $\begin{array}{l}\text { No } \\
\text { Frequency (\%) }\end{array}$ & $\begin{array}{l}\text { Do not know } \\
\text { Frequency (\%) }\end{array}$ \\
\hline $\begin{array}{l}\text { I am afraid of getting AIDS. } \\
\text { Due to awareness of HIV/AIDS, I would be } \\
\text { careful in choosing my partner. }\end{array}$ & $1505(94)$ \\
$\begin{array}{l}\text { People with HIV should be separated } \\
\text { from the normal community life. }\end{array}$ & $1507(94)$ & $50(3)$ \\
$\begin{array}{l}\text { Have you ever had a blood test for HIV/AIDS? (although you never had sex) } \\
\text { I think I have heard enough about HIV/AIDS. }\end{array}$ & $272(17)$ & 126 (77) \\
I prefer to keep away from those infected with HIV. & $496(31)$ & $123)$ \\
\hline
\end{tabular}

Table 5. Responses regarding student's belief towards HIV/AIDS.

\begin{tabular}{|c|c|c|c|}
\hline \multirow[b]{2}{*}{ Statements/questions } & \multicolumn{3}{|c|}{ Responses } \\
\hline & $\begin{array}{l}\text { Yes } \\
\text { Frequency (\%) }\end{array}$ & $\begin{array}{l}\text { No } \\
\text { Frequency (\%) }\end{array}$ & $\begin{array}{l}\text { Do not know } \\
\text { Frequency (\%) }\end{array}$ \\
\hline AIDS is a punishment from God. & $771(48)$ & $363(23)$ & $455(29)$ \\
\hline AIDS is created by someone in the laboratory. & $136(9)$ & $913(57)$ & $543(34)$ \\
\hline Condom promotion does not reduce HIV/AIDS, instead it promotes it. & $1197(75)$ & $209(13)$ & $182(12)$ \\
\hline Condom promotion has no real effect on the spread of this sickness. & $737(46)$ & $604(38)$ & $248(16)$ \\
\hline $\begin{array}{l}\text { Young people should be taught } \\
\text { about sex, HIV/AIDS already in high school. }\end{array}$ & $1428(89)$ & $99(6)$ & $60(5)$ \\
\hline $\begin{array}{l}\text { Teaching young people about sex } \\
\text { and use of condoms encourages them to have sex. }\end{array}$ & $828(52)$ & $556(35)$ & $210(13)$ \\
\hline
\end{tabular}


Table 6. Knowledge score according to the province.

\begin{tabular}{cccc}
\hline Province & $\mathrm{N}$ & Mean & Std. \\
\hline Central & 80 & 79.73 & 14.60 \\
Gulf & 33 & 81.17 & 16.28 \\
Milne Bay & 45 & 80.63 & 12.33 \\
Western & 31 & 78.34 & 20.53 \\
Oro & 20 & 84.64 & 14.20 \\
Morobe & 111 & 80.05 & 14.33 \\
Madang & 160 & 76.72 & 13.12 \\
East Sepik & 159 & 76.36 & 14.28 \\
West Sepik & 54 & 78.90 & 14.99 \\
Eastern Highland & 59 & 78.93 & 14.85 \\
Simbu & 89 & 85.47 & 11.25 \\
Western Highland & 150 & 79.36 & 13.79 \\
Enga & 73 & 78.62 & 14.05 \\
Sothern Highland & 60 & 80.77 & 12.44 \\
Manus & 47 & 81.23 & 13.70 \\
West New Britain & 33 & 79.00 & 15.30 \\
East New Britain & 183 & 79.68 & 11.10 \\
New Ireland & 54 & 78.70 & 12.94 \\
Autonomous Region of B & 68 & 79.78 & 12.06 \\
Jiwaka & 33 & 81.17 & 10.49 \\
Mixed parentage & 22 & 78.41 & 10.93 \\
other countries & 11 & 80.194 & 16.31 \\
NCD & 2 & 62.50 & 12.62 \\
Total & 1577 & 79.40 & 13.61 \\
\hline
\end{tabular}

Table 7. Knowledge score according to the Religious affiliation and institution.

\begin{tabular}{cccccccc}
\hline Religion & $\mathrm{N}$ & Mean & Std.D. & Institutions & $\mathrm{N}$ & Mean & Std. D. \\
\hline Catholic & 607 & 79.25 & 13.64 & DWU & 291 & 80.26 & 12.37 \\
Lutheran & 191 & 79.09 & 13.85 & UPNG & 261 & 80.73 & 14.13 \\
United Church & 121 & 78.66 & 14.51 & UNITECH & 181 & 78.80 & 15.01 \\
SDA & 181 & 79.83 & 13.20 & UOG & 218 & 80.60 & 13.25 \\
AOG & 103 & 80.33 & 12.26 & UoVudal & 94 & 83.96 & 11.71 \\
Christian-Revival & 343 & 79.49 & 13.35 & SMVunapope & 78 & 80.54 & 11.47 \\
Anglican & 8 & 82.14 & 13.49 & Holy Trinity & 149 & 76.82 & 13.84 \\
CRC & 3 & 78.57 & 3.571 & SBKaindi & 96 & 77.90 & 12.91 \\
Baptist & 12 & 85.41 & 15.56 & MTC & 90 & 75.75 & 13.32 \\
Apostolic & 3 & 82.14 & 5.05 & LSoN & 62 & 77.41 & 14.44 \\
Total & 1572 & 79.43 & 13.52 & MATECHCO & 36 & 72.71 & 15.90 \\
& & & & Maritime & 30 & 77.85 & 13.73 \\
& & & & Total & 1586 & 79.40 & 13.58 \\
\hline
\end{tabular}

Table 8. Analysis of variance of knowledge score by province.

\begin{tabular}{lcccc}
\hline Source & $\mathrm{d} f$ & $F$ & $\eta^{2}$ & $p$ \\
\hline province & 22 & 1.95 & 356.78 & .005 \\
Within Groups & 1554 & & \\
error & & & \\
Analysis of variance of knowledge score by for institution & & .000 \\
institution & 11 & 3.738 & 676.964 & \\
Within Groups & 1574 & & & \\
error & & & \\
Analysis of variance of knowledge scores by and belief that people with HIV should be separated \\
Source & $\mathrm{d} f$ & $F$ & $\eta^{2}$ & .000 \\
province & 2 & 16.239 & 2900.819 & \\
Within Groups & 1591 & & & \\
error & 1593 & &
\end{tabular}

Analysis of variance for the knowledge score and belief that AIDS is punishment from God

$\begin{array}{lllll}\text { institution } & 2 & 15.533 & 2822.783 & .000\end{array}$

Within Groups 1586

error 1588 


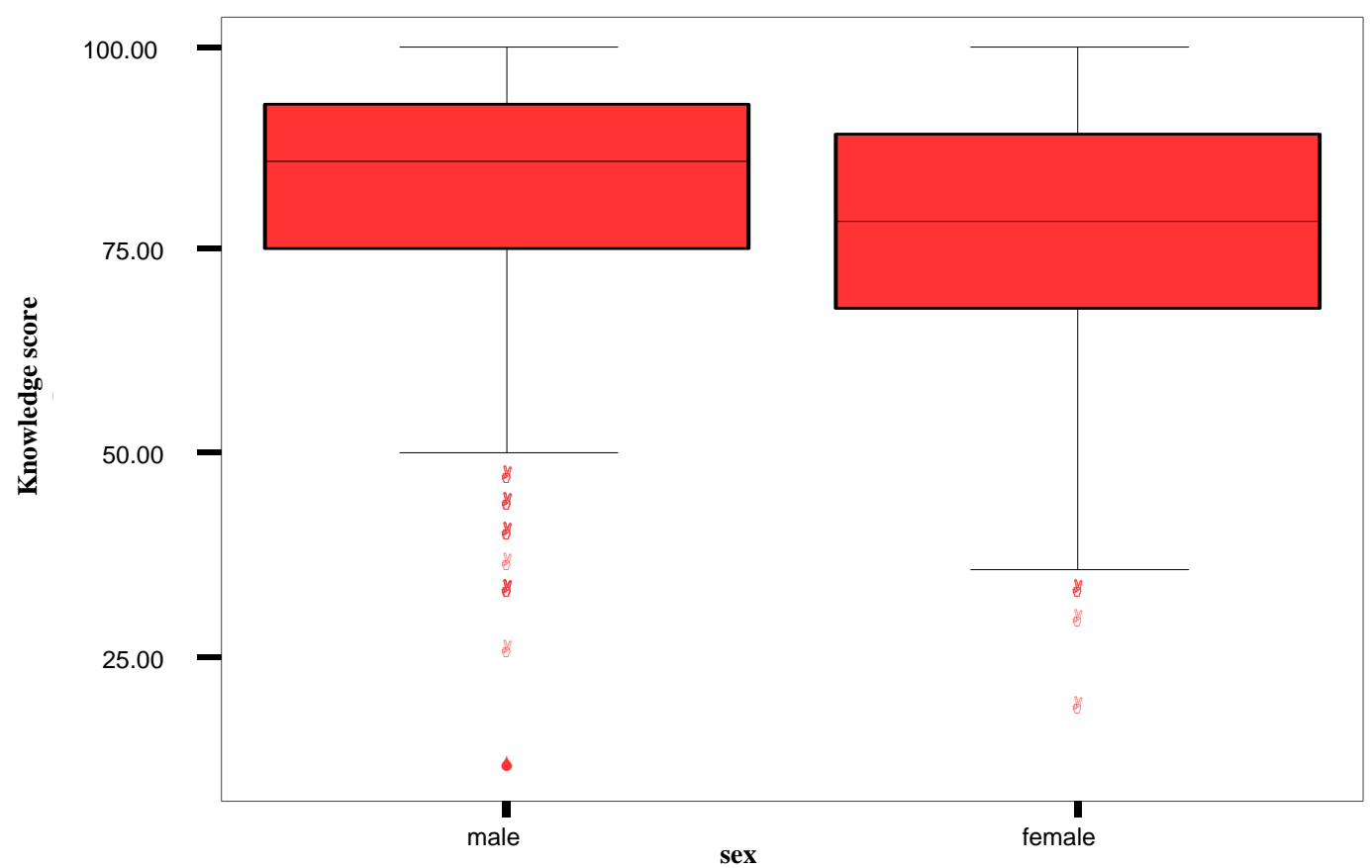

Figure 2. Box plot of the knowledge score of male and female students.

fered among the three categories of respondents, $F(2$, $1591)=16.24, p=.000$. Post hoc analyses were performed using the Duncan test to identify where differences exist. The analyses revealed that respondents with a "No" answer differed significantly from those answered "Yes" and "Do not Know" ( $p=.05)$. The box plot, Figure 3, gives a graphic picture of the difference.

As Table 8 further shows, an analysis on the statement "AIDS is a punishment from God", showed that knowledge on HIV/AIDS significantly differed among the three categories of respondents, $F(2,1586)=15.53$, p $=.000$. Post hoc analyses were performed using the Duncan test to identify where differences exist. The analyses revealed that the knowledge of respondents with a "No" answer differed significantly from those who answered "Yes" and "Do not Know" ( $p=.05)$. Figure 4 gives a graphic picture of the difference.

\section{Discussion}

\subsection{Knowledge Regarding HIV/AIDS}

Overall the responses of the students indicate that they are well informed about HIV/AIDS, as Figure 1 shows more than $75 \%$ of the students have good to very good knowledge of HIV/AIDS. However, when a specific question was asked, whether men or women were more vulnerable to HIV/AIDS interestingly 44\% responded that women were more vulnerable than men, 30\% did not agree, while $26 \%$ were not sure. This could be due to various factors, such as, first of all, culturally in Papua New Guinea, men view women to be there to serve them and this also extends to satisfying men's sexual needs. Women were socialized to serve men and in many cases, women feel obliged to submit to their husbands' demands for sex. Secondly, when men are drunk, they become aggressive in forcing women to submit to sex. This puts women in a very vulnerable position as very often, they fear being beaten up, or chased out of the house and this could create a scene in the community. Sometimes women submit to their husbands to protect their children. It could also be that women tend to be more concerned about their health to consult clinics and find out about their health status than men, hence, more "women cases" are reported and known compared to men. It is also commonly talked about that women in the sex trade sometimes do not use condoms because the men who pay them demand them not to use condoms and so they are vulnerable to HIV/AIDS infection more than their male counterparts.

There have been reports that condoms are not $100 \%$ safe when they are not used appropriately and constantly and therefore do not greatly reduce the risk of transmitting AIDS [13]. In this study, perhaps the most divided opinion (43\% each stated "Yes" and "No" and the remaining 14\% stated “do not know") was on the statement that "the use of condoms during intercourse greatly reduces the risk of transmitting AIDS". With regard to condom promotion, students were to respond to two 


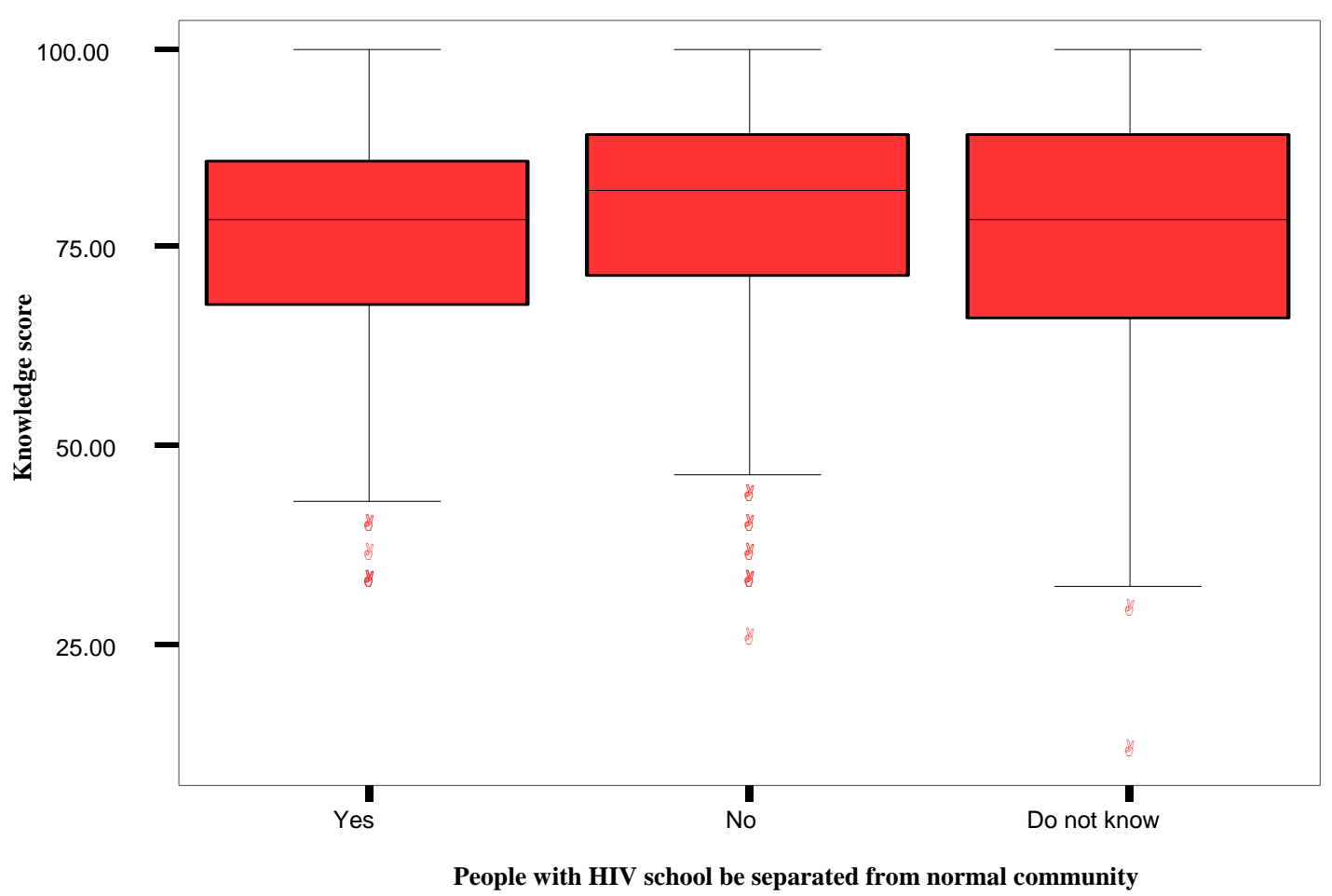

Figure 3. Box plot of the difference in the knowledge in relation to belief and attitude.

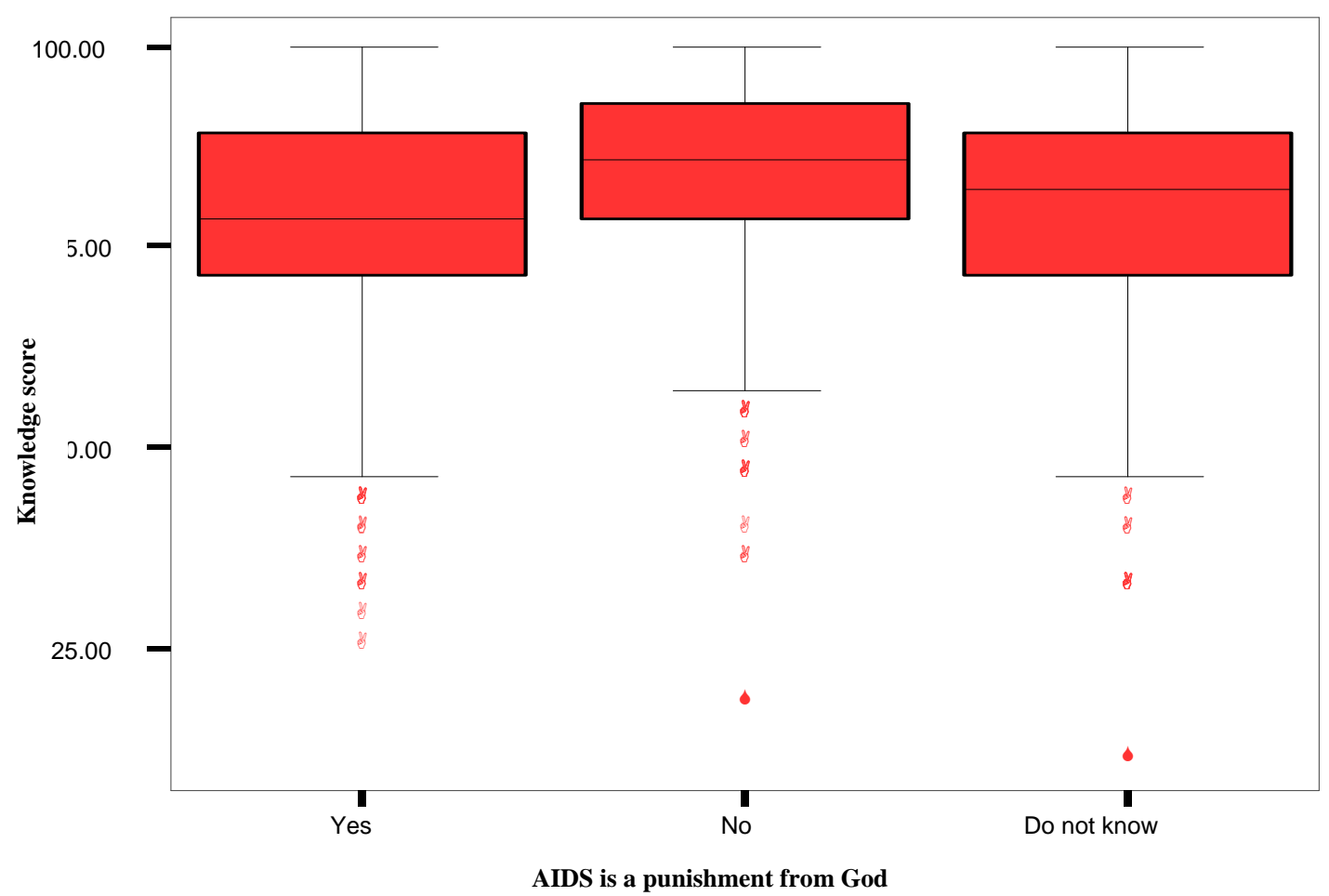

Figure 4. Box plot of the difference in the knowledge in relation to belief.

separate statements, one positive and the other negative, for instance, about $75 \%$ of the students said "Yes" to the statement that "condom promotion does not reduce HIVIAIDS, instead it promotes it", while in another 
statement, "condom promotion has no real effect on the spread of HIVIAIDS", 46\% stated "Yes" and 38\% reported "No" and about $16 \%$ were not sure about the answer.

Does the role of religion affect the result of these findings on condoms? A cross tabulation showed no significant differences in the opinion of 11 religious groups that were part of this study. Furthermore, although no studies were reported, it is widely known that the teachers find it difficult to explain the use and effectiveness of condom as a preventive measure of HIV/AIDS in a classroom setting. Therefore, perhaps the respondents lack a convincing and a scientific presentation on the effectiveness of condoms on the prevention of HIV/AIDS.

When asked if they ever had a blood test for HIV (even if they never had sexual intercourse), only 23\% of the students answered that they had a test while about $76 \%$ had not tested. Perhaps this is one area where usefulness of this study could find its significance. All the tertiary institutions across the country could make it a matter of priority perhaps during the orientation week for the first year students.

\subsection{Attitudes of Respondents with Regard to HIV/AIDS}

This study has shown that in general the students depict a positive attitude towards those infected with HIV/AIDS. Although the great majority (94\%) of the students is afraid of getting the disease, only about $49 \%$ say that they prefer to keep away from those infected with the disease. When asked if people with HIV should be separated from the normal community life, 77\% disagreed, which may well be considered a very healthy attitude and approach towards the victims. It could also be an indication of the good knowledge on HIV/AIDS. In spite of the various seminars, classes and inputs on HIV/AIDS, more than $59 \%$ of the students still think that they have not heard enough about this disease yet. Due to the awareness of HIV/AIDS, if they would be careful in choosing their partner, a vast majority (94\%) of students responded "Yes". Although there are clear indications of a rather good knowledge on HIV/AIDS, a lot more can be done and needs to be done, particularly more of educational programs, because about $89 \%$ of the respondents, in this study, stated that young people already in high schools should be taught about sex and HIV/AIDS.

\subsection{Beliefs in Regard to HIV/AIDS}

Interestingly, this study has revealed that nearly half of the students at the tertiary level believe that AIDS is a punishment from God (48\%) and about 29\% are not sure while only about $23 \%$ say "No" with certainty. Is there a possibility of the influence of religion in these findings? Although we may never know the real impact of religious influence on the attitude of the people, an ANOVA test has clarified that there is no significant difference $F(7,1558)=.557 ; \mathrm{P}=.791$, between different religious groups with regard to their belief that the HIV/AIDS is a punishment from God.

When asked if they believed whether AIDS was created by someone in a laboratory, only about $9 \%$ thought so, $57 \%$ did not think so and $34 \%$ did not know. Although about $89 \%$ think that young people should already be taught about HIV/AIDS in high school, about $52 \%$ think that teaching young people about sex and the use of condoms would encourage them to have sex, while $35 \%$ disagreed to that view and about $13 \%$ were not sure.

\subsection{Knowledge in Relation to Demographic Va- riables}

Perhaps one of the interesting findings of this study was that male students showed slightly better knowledge of HIV/AIDS than female students. One of the possible reasons could be that there is perhaps more peer education among the boys than the girls and that the males find it comfortable talking and learning about HIV/AIDS more than females who may be a bit shy or uncomfortable to talk about such an issue

The researchers expected that there could be a difference in the knowledge level between the institutions because of the nature of a study program such as health sciences or nursing programs, or other health related programs offered in some institutions. But the analysis of data showed a significant difference, and interestingly it was not within any institutions that offered health related programs. It was the University of Vudal that had a significant difference in level of knowledge compared to other institutions. It could be that the students from the Vudal probably had an awareness program in the recent past.

The ANOVA test also showed a moderate difference in the knowledge level of the students between the provinces. However, no significant difference was found on the basis of religious affiliation or occupation of the parents. Perhaps these findings are an indication of the fact that the HIV/AIDS awareness programs, education and information on HIVAIDS are more effectively done at the level of provinces no matter what religious or family background one comes from.

It also appears that the students' attitude towards people infected with the disease is more accepting and compassionate. For example, the majority of the students did not agree with the idea that those infected with HIV+ should be separated from their communities. It is also 
important to note that more than half of the students do not agree that they would keep away from those infected. Such an attitude should be seen as a very healthy approach and needs to be further encouraged in confronting this pandemic.

When asked if they ever had a blood test for HIV (even if they never had sexual intercourse), about 23\% answered that they did get tested for HIV while a majority of the students (75\%) had not had any blood test. Perhaps here is an area where the administration of the different tertiary institutions could offer assistance; rightfully motivating students in order to undergo the test and to undergo necessary medication if necessary.

It is also very encouraging to note that a majority of tertiary students have a considerate and compassionate attitude toward those infected with HIV/AIDS. The respondents were asked if those that were infected should be removed from normal community life, most of the student's disagreed with this idea. This could well be due to the correct understanding of the nature and transmission of HIV/AIDS, i.e., there is nothing to be afraid of to live with or to go near the people who are infected.

Overall, the high level of knowledge of tertiary students about the transmission and causes of HIV/AIDS and a considerate and compassionate attitude towards people who are infected, signals, to a large extent, rather positive and healthy attitudes and beliefs regarding HIV/AIDS among the young educated people of Papua New Guinea, and are indeed signs of hope for a better future.

\subsection{Implications of the Findings}

Educators at all levels, be it primary, secondary or tertiary, play crucial roles in disseminating the right knowledge, healthy attitudes and beliefs regarding HIV/AIDS among the young people. Perhaps, the findings of this study could be used as guidelines in the development of an effective curriculum and education programs in educational institutions of at all levels. The following are some of the suggestions:

More than half of the students think they did not have enough information on HIV/AIDS and about 75\% think that education on sex, HIV/AIDS should already be given at the high school levels. Therefore, we recommend that new educational strategies and programs regarding sex education and HIV/AIDS should be planned and implemented at all schools throughout PNG, if it is not already begun.

One of the most divided opinions of students in this study was on the effectiveness of use of condoms to prevent the spread HIV/AIDS. We recommend that doctors or other trained health workers be invited to give a more scientific and convincing presentation of the effective- ness of the use of condoms as a preventive measure for HIV/AIDS.

Based on this study's data, less than $25 \%$ of the students ever had a blood test; it is recommended that all the tertiary students at the time of their entry into tertiary institution be subjected to a compulsory HIV/AIDS test, which could pave way for preventive measures.

Since the study has also shown that nearly $50 \%$ of the tertiary students believe that AIDS is a punishment of God, and this belief tends to affect the basic knowledge on HIV/AIDS, we recommend that educators and health workers be made aware of such a reality and they should be prepared to give a clinical and scientific explanation of the origin of this pandemic.

Since a vast majority of the students have expressed their fears of getting AIDS and that they will be careful in choosing their partners, it is recommended that negotiation skills for discussing sexual behaviours and options with partners be taught in the classroom along with sexual decision-making strategies.

\section{General Conclusions}

In the light of above findings we draw the following conclusions:

The research showed that most of the students have a good level of knowledge regarding HIV/AIDS, which is to be taken as a good sign, however, this should not be an excuse to reduce the massive awareness campaigns being conducted throughout the country. If more people are aware of the basic information on the root causes of the disease, they would have informed opinions about sexual behaviors and positive attitudes towards HIV/AIDS victims. The findings also indicate that the tertiary students are aware of the seriousness of the disease and it is the responsibility of the educators to keep the momentum going. Perhaps the most encouraging fact is that students overall show a considerate and compassionate attitude towards those infected. Students also indicate a positive and healthy attitude towards those infected with HIV/AIDS, which could be due to accurate knowledge of this disease. Regardless of the study institution there is no significant difference in the level of knowledge of the students on HIV/AIDS. This perhaps implies almost all the tertiary level institutions have good HIV/AIDS awareness classes or campaigns.

\subsection{Limitations}

Although, this study is the first of its kind to be conducted among the tertiary students and it has revealed many interesting facts, this study has its limitations. First of all, the questionnaire was a researcher made, although with due consideration and consultation, it still could be improved with different factors clearly distinguished. 
Secondly, since the questionnaire was a "self-report measure" the possibility of bias cannot be ruled out, perhaps a personal interview might give much more in-depth information. Thirdly, there is a possibility of selection bias as only first year students were selected for this study.

\subsection{Recommendations}

It is highly likely that HIV/AIDS will still dominate as one of the main health concerns of the nation for years to come. As education has been found to be one of the most powerful tools to contain this pandemic, educators should take professional and moral responsibility to proactively implement HIV/AIDS education and prevention strategies in their respective institutions. As this study has shown there is a momentum and it is equally the responsibility of educators to keep it going.

The findings of this study clearly indicate that educators must provide more than just accurate information about HIV/AIDS. They must be aware of the differences between men and women's attitudes and behaviours with regard to HIV/AIDS. It is important for future research to focus on: a) the level of knowledge of the staff or other educators on the same issue, in order to ensure that they impart right knowledge and attitude; and b) methods which help students to realistically assess their risk for HIV/AIDS.

\section{Acknowledgements}

This research was funded by the National AIDS Council of PNG.

\section{REFERENCES}

[1] “AIDS Epidemic Update. Geneva,” UNAIDS/WHO, December 2007.

[2] J. D, Baldwin and J. I. Baldwin, "Factors Affecting AIDS
Related Sexual Risk Taking Behavior among College Students,” Journal of Sex Research, Vol. 25, No. 2, 1988, pp. 181-196. doi:10.1080/00224498809551454

[3] T. Barnes, "The Impact of HIV/AIDS on the University of the Western Cape," A Report for the Association for the Development of Education in Africa, 2000.

[4] A. K. Harding, E. C. Anadu, L. A. Gray and D. A. Champeau, “Nigerian University Students' Knowledge, Perceptions, and Behaviors about HIV/AIDS: Are These Students at Risk?” Journal of Social Health, Vol. 119, No. 1, 1999, pp. 23-31.

[5] J. Hubley, "Health Empowerment, Health Literacy and Health Promotion Putting It All Together,” 2002. http://www.hubley.co.uk/1hlthempow.htm (Accessed on May 14, 2009)

[6] M. J. Kelly, “Challenging the Challenger: Understanding and Expanding the Response of Universities in Africa to HIV/AIDS,” ADEA Working Group on Higher Education, World Bank, Washington, 2001.

[7] “The STI, HIV and AIDS,” Six Monthly Surveillance Report, Port Moresby, 2008.

[8] “The STI, HIV and AIDS,” Annual Surveillance Report, December 2009.

[9] “National HIV/AIDS Support Project.” http://staging.nacs.org.pg/resources/docments/Annual_Pla n_2006.pdf

[10] "National HIV and AIDS Strategy," National AIDS Council Secretariat, NCD, Papua New guinea, 2011-15, pp. 15-19.

[11] “National AIDS Council Secretariat," National Department of Health STI, HIV and AIDS Surveillance Report: NCD, Papua New guinea, 2011-15.

[12] “UNAIDS’ AIDS Epidemic Update,” December 2000.

[13] "HIV Transmission," University at Albany University HIV/AIDS Information Center (UA AIDS INFO), 3 July 2009.

http://www.albany.edu/sph/AIDS/aids101 2.html 